\title{
The challenge of fistula closure in Crohn's disease: an endoscopic technique for closure of a fistula
}
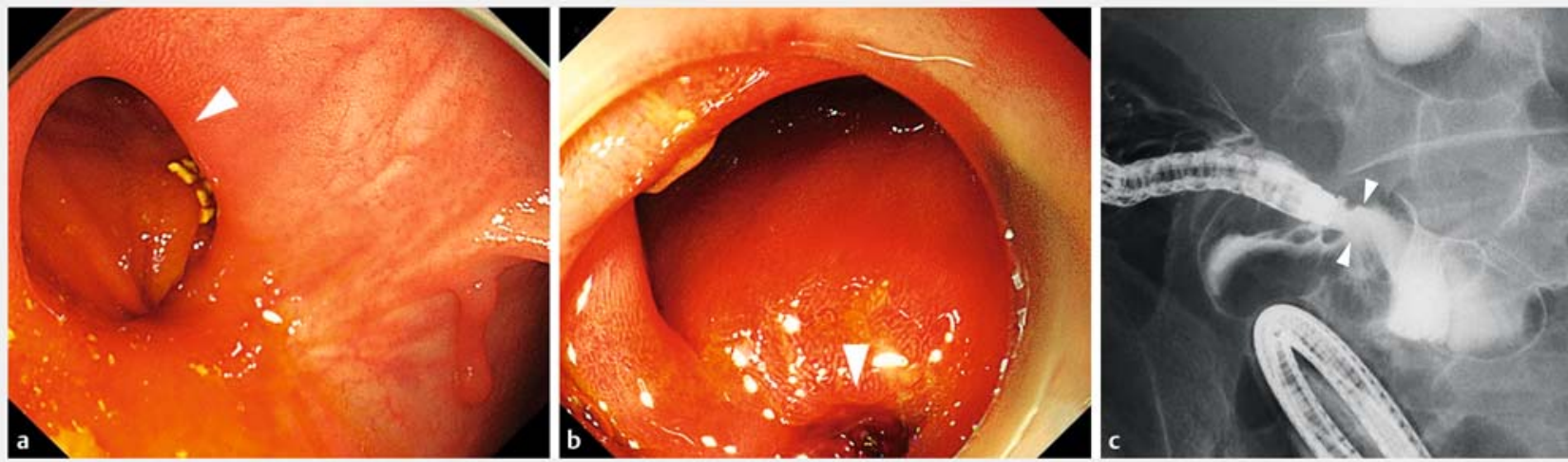

- Fig. 1 Colonoscopy revealed a cecal-sigmoid fistula as observed from: a the sigmoid colon; $\mathbf{b}$ the cecum. $\mathbf{c}$ Elective colonography revealed a cecal-sigmoid fistula of $10 \mathrm{~mm}$ in diameter.

Crohn's disease is associated with many intestinal complications, such as stenosis and fistula, and many cases require intestinal resection during the course of the disease. Although anti-tumor necrosis factor $\alpha$ (TNF $\alpha)$ agents are effective in inducing remission of active Crohn's disease, they are ineffective for certain intestinal complications, such as fistulas [1]. We attempted endoscopic closure for a patient in whom anti-TNF $\alpha$ agents were not effective in treating the fistula. The patient was a 52-year-old man with ileal- and colonic-type Crohn's disease who was receiving maintenance treatment with infliximab. He had been experiencing sudden bowel movements and watery stool for several years owing to a cecal-sigmoid fistula that had not closed with infliximab treatment. Colonoscopy revealed a cecal-sigmoid fistula that allowed a 10.8-mm endoscope to be passed through it ( $\mathbf{F i g . 1}$ ).

We obtained informed consent from the patient and attempted endoscopic closure of this fistula ( $\triangleright$ Fig. 2 ; $\triangleright$ Video 1 ). An endoscopic purse-string suture with a nylon loop and clips was placed using a two-channel scope. Although complete closure was not achieved, the fistula
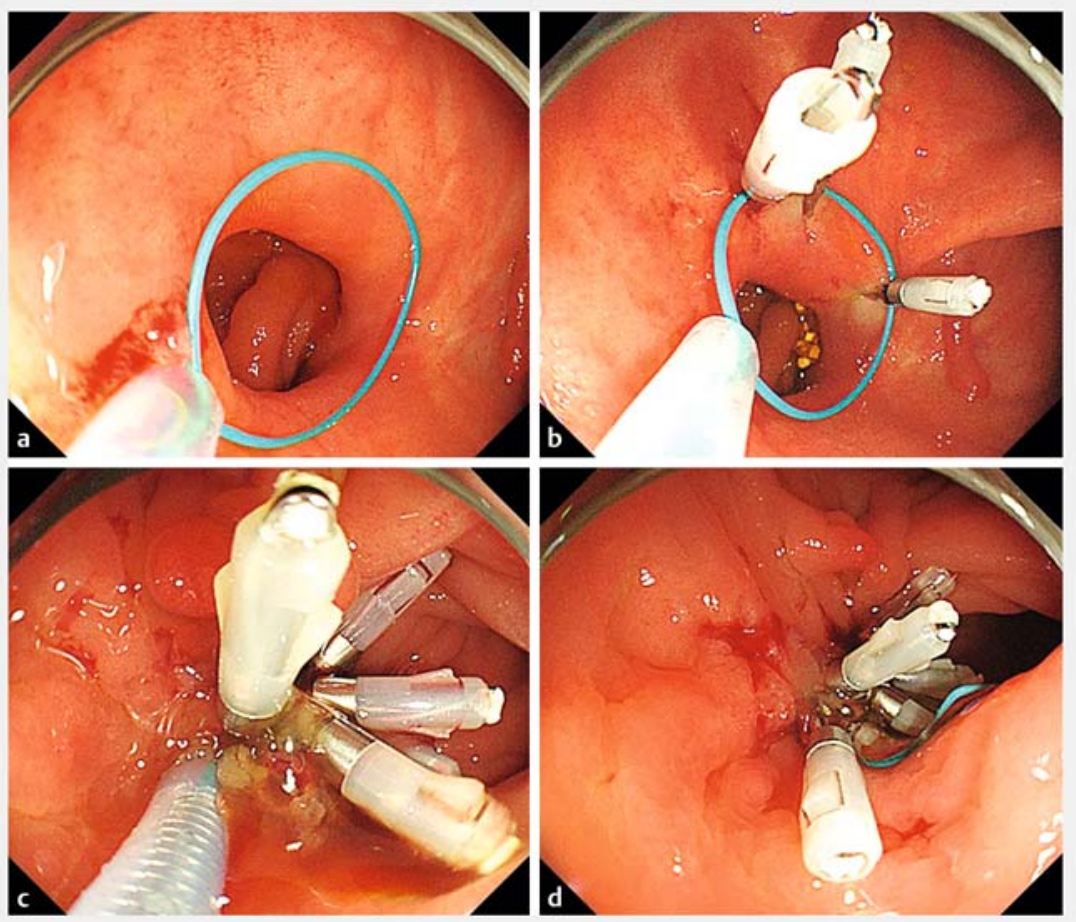

- Fig. 2 Endoscopic views showing the procedure used to close the fistula. a The operator placed a nylon loop on the margin of the fistula using a two-channel endoscope. $\mathbf{b}$ The nylon loop was clipped to the margin of the fistula from the distal to the proximal end on both sides. c The assistant tightened the handle of the nylon loop to narrow it and close the fistula. d Additional clipping was performed on the proximal side to prevent the nylon loop from detaching. 

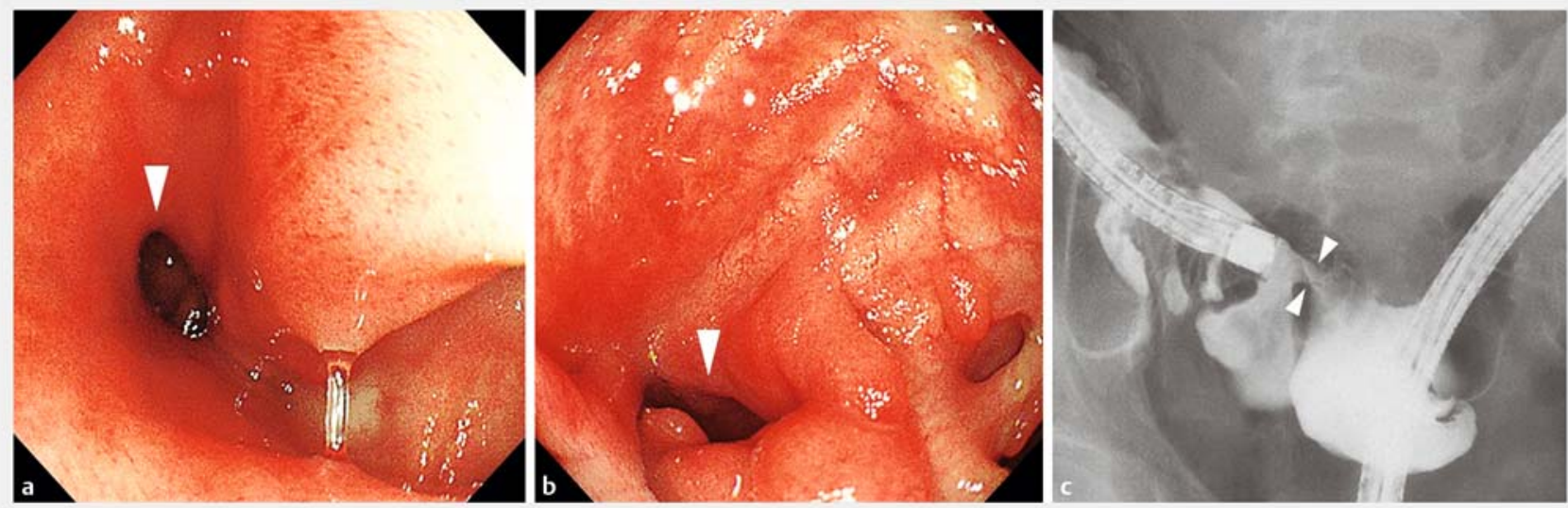

Fig. 3 Colonoscopy 4 months after fistula closure revealed a cecal-sigmoid fistula as observed from: a the sigmoid colon; $\mathbf{b}$ the cecum. c Elective colonography confirmed a cecal-sigmoid fistula of $4 \mathrm{~mm}$ in diameter, meaning a 10.8 -mm endoscope could no longer be passed through it.

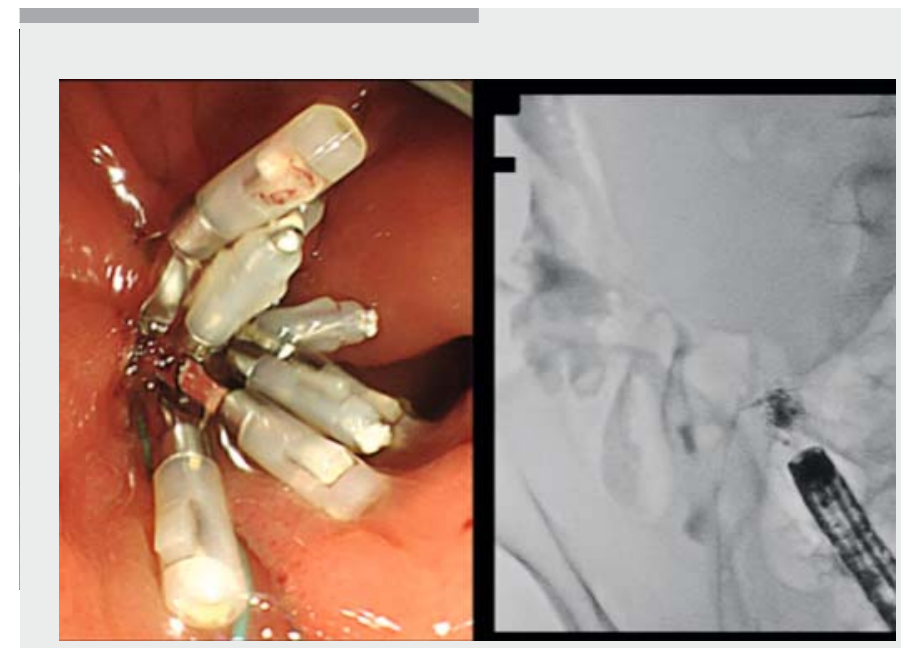

$\nabla$ Video 1 Endoscopic closure using a purse-string suture for a cecal-sigmoid fistula.

shrank and the patient's subjective symptoms markedly improved ( $\bullet$ Fig. $\mathbf{3}$ ).

The efficacy of anti-TNF $\alpha$ agents for fistulas in Crohn's disease is limited, and the number of fistulas is a predictor of the closure rate [2]. In recent years, endoscopic purse-string sutures and endoscopic closure using over-the-scope clips (OTSCs) have been applied not only to massive gastrointestinal perforations during endoscopic submucosal dissection, but also to intestinal fistulas, enterocutaneous fistulas, and gastrogastric fistulas, among others [3-5].

\section{Competing interests}

The authors declare that they have no conflict of interest.

The authors

Satohiro Matsumoto, Hirosato Mashima Department of Gastroenterology, Saitama Medical Center, Jichi Medical University, Saitama, Japan

\section{Corresponding author}

\section{Satohiro Matsumoto, MD, PhD}

Department of Gastroenterology, Saitama Medical Center, Jichi Medical University, 1-847 Amanuma, Omiya, Saitama, Saitama 330-8503, Japan

Fax: $+81-48-6485188$

s.w.himananon@ac.auone-net.jp

This is the first report of endoscopic fistula closure in a patient with Crohn's disease. Asymptomatic internal fistulas can be followed up, but for patients with Crohn's disease who have symptomatic fistulas, such as the one reported here, endoscopic fistula closure is a minimally invasive procedure and should be considered as a viable treatment option.

Endoscopy_UCTN_Code_TTT_1AQ_2AG

\section{References}

[1] Lee M], Parker CE, Taylor SR et al. Efficacy of medical therapies for fistulizing Crohn's disease: systematic review and meta-analysis. Clin Gastroenterol Hepatol 2018; 16: 18791892

[2] Kobayashi T, Hishida A, Tanaka H et al. Realworld experience of anti-tumor necrosis factor therapy for internal fistulas in Crohn's disease: a retrospective multicenter cohort study. Inflamm Bowel Dis 2017; 23: 22452251 
[3] Wedi E, Gonzalez S, Menke D et al. One hundred and one over-the-scope-clip applications for severe gastrointestinal bleeding, leaks and fistulas. World J Gastroenterol 2016; 22: 1844-1853

[4] Mukewar S, Kumar N, Catalano M et al. Safety and efficacy of fistula closure by endoscopic suturing: a multi-center study. Endoscopy 2016; 48: 1023-1028

[5] Roy J, Sims K, Rider P et al. Endoscopic technique for closure of enterocutaneous fistulas. Surg Endosc 2019; 33: 3464-3468
Bibliography

Endoscopy 2021; 53: E55-E57

DOI 10.1055/a-1173-8540

ISSN 0013-726X

published online 19.6.2020

(c) 2020. Thieme. All rights reserved.

Georg Thieme Verlag KG, Rüdigerstraße 14,

70469 Stuttgart, Germany

\section{ENDOSCOPY E-VIDEOS}

https://eref.thieme.de/e-videos

口回 Endoscopy E-Videos is a free 登视 靣: on interesting cases and new techniques in gastroenterological endoscopy. All papers include a high quality video and all contributions are freely accessible online.

This section has its own submission website at

https://mc.manuscriptcentral.com/e-videos 